\title{
A comparative study of a range of polymeric microspheres as potential carriers for the inhalation of proteins.
}

\section{$\operatorname{AUTHOR}(\mathrm{S})$}

Neeraj Sivadas, Desmond O'Rourke, Aoife Tobin, Zeibun Ramtoola, John G. Kelly, Anthony J. Hickey, SallyAnn Cryan

\section{CITATION}

Sivadas, Neeraj; O'Rourke, Desmond; Tobin, Aoife; Ramtoola, Zeibun; Kelly, John G.; Hickey, Anthony J.; et al. (2008): A comparative study of a range of polymeric microspheres as potential carriers for the inhalation of proteins.. Royal College of Surgeons in Ireland. Journal contribution.

https://hdl.handle.net/10779/rcsi.10798511.v1

\section{HANDLE}

10779/rcsi.10798511.v1

\section{LICENCE}

\section{BY-NC-SA 4.0}

This work is made available under the above open licence by RCSI and has been printed from https://repository.rcsi.com. For more information please contact repository@rcsi.com

URL

https://repository.rcsi.com/articles/journal_contribution/A_comparative_study_of_a_range_of_polymeric_micro spheres_as_potential_carriers_for_the_inhalation_of_proteins_/10798511/1 
Title:

A comparative study of a range of polymeric microspheres as potential carriers for inhalation of proteins

Authors: Neeraj Sivadas ${ }^{1}$, Desmond O' Rourke ${ }^{1}$, Aoife Tobin ${ }^{1}$, Vivienne

Buckley ${ }^{1,3}$, Zeibun Ramtoola ${ }^{1}$, John G. Kelly ${ }^{1}$, Anthony J Hickey², Sally-Ann

Cryan $^{* 1}$

${ }^{*}$ Corresponding author

${ }^{1}$ School of Pharmacy

Royal College of Surgeons in Ireland

York House, York Street, Dublin 2, Ireland

Phone: (01) 4022741, Fax: (01) 4022765

Email: scryan@rcsi.ie

2 Division of Molecular Pharmaceutics

School of Pharmacy

The University of North Carolina

Chapel Hill, NC 27599-7360, USA

Phone: (919) 966-0484

${ }^{3}$ Immune Regulation Research Group,

School of Biochemistry and Immunology,

Trinity College, Dublin, Ireland 


\section{Abstract:}

2 The aim of this study was to compare protein-loaded inhalable microparticles

3 manufactured using a range of biocompatible polymers including hydroxypropyl cellulose 4 (HPC), chitosan, hyaluronic acid, alginate, gelatin, ovalbumin and poly (lactide-co5 glycolide)(PLGA). Spray drying was used to prepare microparticles containing bovine 6 serum albumin labeled with flourescein isothiocyanate (BSA-FITC). Particles of respirable

7 size and high protein loading were obtained. No evidence of BSA degradation was seen 8 from PAGE analysis. The microparticles were mixed with mannitol as a carrier and

9 powder aerosolization was assessed with a multi-dose dry powder inhaler (DPI) using a

10 multi-stage cascade impactor. The mass median aerodynamic diameter (MMAD) ranged

11 between $2.9-4.7 \mu \mathrm{m}$. Potential polymer toxicity in the lungs was compared by impinging

12 the particles on Calu-3 monolayers and assessing the cytotoxicity, induction of cytokine

13 release, changes in transepithelial permeability and electrical resistance. No toxic effects

14 were observed with most of the polymers though some evidence of compromised cell

15 monolayer integrity was seen for PLGA and ovalbumin. PLGA and gelatin microparticles

16 caused a significant increase in IL-8 release. Of the polymers studied, PLGA showed the

17 greatest toxicity. Certain polymers showed particular promise for specific protein delivery

18 needs in the lungs, such as HPC to improve flow properties, sodium hyaluronate for

19 controlled release, and chitosan and ovalbumin for systemic delivery.

Keywords: Pulmonary drug delivery; protein; microparticles; calu-3; toxicity. 


\section{Introduction}

Inhalation therapy is a widely used and well accepted treatment for many lung diseases. As a portal for non-invasive drug delivery, the pulmonary route is attractive. The lungs possess many favorable characteristics including a large absorptive surface area $\left(100 \mathrm{~m}^{2}\right)$, extensive vasculature, thin alveolar epithelium (0.1-0.2 $\left.\mu \mathrm{m}\right)$ and short distance of air-blood exchange passage (Patton et al., 1992). There has been particular interest in pulmonary delivery of macromolecules for both local and systemic delivery (Scheuch et al., 2006). The most notable being inhaled insulin. Exubera, a dry powder form of insulin was approved in early 2006 but was recently removed from the market (Mack, 2007). Inhalation of proteins/peptides is not without its difficulties. These can include protein denaturation during manufacture, aerosolization and storage, poor powder flowability resulting in inefficient delivery, rapid clearance from the lungs due to mucociliary clearance, enzymatic degradation and phagocytosis by alveolar macrophages (Boer et al., 2001).

Several approaches have been used to overcome these problems. One of the most versatile strategies is the bioengineering of inhalable particles using biocompatible polymers. Such polymers have been used to improve protein stability and enhance their absorption via the lungs (Sakagami et al., 2001), improve particle aerodynamic properties (Sham et al., 2004), achieve controlled/sustained release (Huang et al., 2002) or escape the natural phagocytic clearance in the lungs (Edwards et al., 1997). Many of these formulations have yet to be commercialised and this delay can be attributed to many factors including: a lack of comparative data on polymer influence on the aerodynamic properties of dry powders for inhalation, the lack of licensed excipients and standardized 
1 biopharmaceutical testing methods for the pulmonary route, and concerns regarding the 2 safety and clearance of these polymers from the lungs.

This study sought to compare a range of polymers including proteins, polyesters or water-soluble derivatives of proteins and sugars. These included sodium alginate, chitosan, 5 gelatin, hydroxy propyl cellulose, PLGA, ovalbumin and sodium hyaluronate. Some of these 6 have been investigated as potential carriers for the treatment of diseases such as 7 tuberculosis (Suarez et al., 2001; Bivas-Benita et al., 2004; Zahoor et al., 2005), diabetes

8 (Surendrakumar et al., 2003), asthma (Sakagami et al., 2002) and osteoporosis (Morimoto 9 et al., 2000). Mucoadhesive polymers such as chitosan, sodium hyaluronate and HPC have been found to increase pulmonary absorption by delaying mucociliary clearance (Sakagami

11 et al., 2001). Gelatin, albumin and PLGA have been found suitable for the targeting and controlled delivery of candidates such as salmon calcitonin, tetrandine and insulin to the

13 lungs (Zeng et al., 1995; Edwards et al., 1997; Morimoto et al., 2000). The utility of such 14 polymers as carriers has therefore been demonstrated in principle. However, little comparative data on the aerodynamic properties or toxicity and immunogenic potential of 16 these polymers is available to allow formulation scientists to assess their usefulness for 17 particular applications, eg. local versus systemic delivery. Inhalable protein-loaded microparticles of the selected polymers were manufactured by spray drying (Okamoto et al., 2002). A comprehensive comparison of the physico20 chemical properties of the microparticles was conducted including - size, morphology, 21 protein-loading and stability, protein release and aerodynamic characteristics. The 22 immortalized human airway epithelial cell line, Calu-3 was used to compare the interaction 23 of the polymeric microparticles with the airway epithelium (Grainger et al., 2006). When 
1 cultured at an air-liquid interface, they form mucus producing, well differentiated and

2 polarized monolayers with tight junctions that generate significant transepithelial electrical

3 resistance (Foster et al., 2000). A simple, yet reproducible system was developed to

4 impinge the microparticles on to Calu-3 monolayers cultured on Transwell ${ }^{\circledR}$ inserts. Cellular

5 response to particle insult was measured in terms of cell viability (Knebel et al., 2002),

6 cytokine (eg. IL-8) release (Abe et al., 2000), transepithelial resistance (Blank et al., 2006)

7 and paracellular permeability (Robledo et al., 1999).

8 2. Materials and methods

$9 \quad 2.1$ Materials

Fraction V Bovine Serum Albumin (BSA), BSA-Fluorescein Isothiocyanate (BSA-

11 FITC), low viscosity alginic acid sodium salt from Macrocystis pyrifera, low molecular weight chitosan, Gelatin (Type B from bovine skin), and albumin, grade II from chicken egg

13 white were purchased from Sigma Chemical Co. (St. Louis, MO, USA). Low viscosity 14 hydroxy propyl cellulose (HPC-L) was a gift from Nippon Soda Co. Ltd., Japan. Sodium

15 Hyaluronate was sourced from Shandong Freda Biochem Co. Ltd.,China. PLGA RG 504H 16 was supplied by Boehringer Ingelheim (Ingelheim, Germany). D-Mannitol (Mannidex®) was

17 a gift from Cerestar, Belgium. All other solvents or chemicals were of HPLC or analytical 18 grade. Calu-3 cells were obtained from American Type Culture Collection (Rockville, MD, 19 USA). Cell culture media and supplements were purchased from Gibco BRL (Paisley, 20 Scotland). Tissue culture plastics were from Sarstedt AG \& Co. (Germany) and Transwell 21 clear polyester inserts $(12 \mathrm{~mm}$ diameter, pore size $0.4 \mu \mathrm{m})$ from Corning Costar (Corning, $22 \mathrm{NY}$ ). 


\section{$1 \quad 2.2$ Spray-drying}

BSA-FITC was dissolved in deionized water at $0.01 \% \mathrm{w} / \mathrm{v}$ and mixed with aqueous solutions $(1 \% \mathrm{w} / \mathrm{v})$ of alginic acid sodium salt, gelatin, HPC-L, ovalbumin or sodium hyaluronate. Chitosan was dissolved in $0.1 \% \mathrm{v} / \mathrm{v}$ HPLC-grade acetic acid. A protein:polymer ratio of 1:100 was used in all cases. In the case of PLGA microspheres, the protein was dissolved in deionized water and emulsified in the organic phase consisting of PLGA dissolved in Dichloromethane. Tween 20, at a concentration of $0.1 \% \mathrm{w} / \mathrm{v}$, was used as the surfactant. The emulsion and above solutions were spray dried through a $0.5 \mathrm{~mm}$ nozzle using a Buchi ${ }^{\circledR} 190$ spray dryer (Buchi, Flawil, Switzerland) with an inlet temperature between $45-140^{\circ} \mathrm{C}$ and a feed flow rate of $4-5 \mathrm{ml} / \mathrm{min}$. The recovered particles were stored in a desiccator at $4^{\circ} \mathrm{C}$ until further use.

\subsection{Determination of size, density and water content}

The particle size of the microparticles was determined by laser diffraction (Malvern Mastersizer 2000, Malvern Instruments Ltd, Malvern, UK) following suspension of the microparticles in isopropyl alcohol/ethanol and bath sonication for one minute. Dry dispersion was employed for particles of HPC-L. Morphological assessment was performed using a Hitachi scanning electron microscope (Model S3500N) after mounting the preparations on studs and sputter-coating with gold (Polaron SC500 Gold Sputter Coater, Quotum technologies, Newhaven, UK). The density $(\rho)$ of the microparticles was determined as the tapped density using a tap density tester (Copley Scientific, Nottingham, UK) (Fiegel et al., 2004). The equilibrium moisture content of the particles was assessed by using a Q-500 thermogravimetric analyzer (TGA) (TA Instruments, New Castle, DE) (Sethuraman et al., 2002). 


\section{$1 \quad 2.4$ Determination of protein loading, stability and distribution}

2

3

4

To determine the protein loading, microsphere samples equivalent to approximately $100 \mu \mathrm{g}$ of protein were dissolved in $10 \mathrm{ml}$ of deionized water and the protein content was analyzed by UV spectrophotometry, at 495nm using a spectrophotometer (Biochrom, UK). In the case of chitosan microparticles, samples were dissolved in $0.1 \%$ acetic acid, precipitated with $0.4 \mathrm{M} \mathrm{NaOH}$ and then centrifuged to remove the polymer prior to analysis (Witschi et al., 1999). PLGA microspheres were disrupted using $2.5 \% \mathrm{SDS} / 0.2 \mathrm{M} \mathrm{NaOH}$.

The resulting mixture was neutralised to $\mathrm{pH} 7$ by stepwise addition of $1 \mathrm{M} \mathrm{HCl}$ (Gupta et al., 1997). To eliminate interference from the reagents used for protein extraction, the samples (from both chitosan and PLGA) were filtered and analysed for BSA content using reversephase HPLC (Perkin Elmer, Model Series 200).The system was equipped with a Gemini $\mathrm{C}_{18}$ column $(5 \mu \mathrm{m}, 250 \times 4.6 \mathrm{~mm}$, Phenomenex, UK) and a UV detector (Perkin Elmer, Model Series 200) using the following conditions: detection wavelength $-220 \mathrm{~nm}$; mobile phase $A: 0.1 \% \mathrm{v} / \mathrm{v}$ trifluoroacetic acid (TFA) in water, mobile phase $\mathrm{B}: 0.08 \% \mathrm{v} / \mathrm{v}$ TFA in acetonitrile; flow rate: $1 \mathrm{ml} / \mathrm{min}$ (Kohn et al., 2007). All determinations were performed in triplicate.

The structural integrity of the encapsulated protein was assessed using Polyacrylamide Gel Electrophoresis (PAGE)(Igartua et al., 1998). BSA extracted from the microparticles was compared with native BSA and low molecular weight reference markers (29-205 kDa) (Sigma). Confocal Laser Scanning Microscopy (CLSM) was carried out using an LSM 510 Axio plan 2 upright confocal microscope (Carl Zeiss, Germany) at original magnification x63 using immersion oil both on the objective and to wet the dry microparticles. A krypton argon laser provided excitation light at $488 \mathrm{~nm}$. 


\section{$1 \quad 2.5$ Determination of aerosolization efficiency}

2

3

An Anderson Cascade Impactor (Copley Ltd., Nottingham, UK) was used to determine the dispersibility and fine particle fraction (FPF) of each powder/carrier blend through a DPI according to the manufacturer's instructions. D-Mannitol (Mannidex ${ }^{\circledR}$, Cerestar, Belgium) was used as the carrier. It was sieved to give particles in the range 60 to $125 \mu \mathrm{m}$. It was then mixed with the microparticles at a ratio of $24: 1$ (mannitol: microparticles). To achieve uniform distribution, the blend was passed three times through a $\# 125 \mu \mathrm{m}$ sieve and further mixed in a glass mortar. Blend content uniformity were investigated by analyzing $50.0 \pm 0.5 \mathrm{mg}$ samples $(n=5)$ of each blend, according to the method described in Appendix XII H, Test B, Uniformity of Content of the British Pharmacopoeia (2004). Content uniformity for all blends gave a relative standard deviation of less than $5 \%$. Each plate of the impactor was coated with a solution of Tween 80 in acetone $(5 \% \mathrm{w} / \mathrm{v})$. Acetone was evaporated by placing the plates in an oven at $60^{\circ} \mathrm{C}$ for 5 minutes. About $25 \mathrm{mg}$ of the blend was manually loaded into the DPI and aerosolized by drawing air at a flow rate of $60 \mathrm{Imin}^{-1}$ for 4 seconds through the impactor. Ten such doses were discharged into the apparatus. The washings from each stage were assayed for the content of BSA-FITC using HPLC (as described previously). The emitted dose (ED) is the total protein mass exiting the inhaler. Uniformity of emitted dose was determined using Apparatus B (Dosage Unit Sampling Apparatus- DUSA)(USP, 2000). Values were deemed acceptable if they were within $75-125 \%$ of the label claim. The recovered dose (RD) was taken as the cumulative mass of protein recovered (inhaler + all stages of the impactor) after each experiment. The Fine particle dose (FPD) was calculated as the quantity of protein recovered from Stage 2 to the Filter. The fine particle fraction (FPF) is the FPD 
1 expressed as a percentage of ED. The experimental mass median aerodynamic diameter

2 (MMAD) and the geometric standard deviation (GSD) of the particles were also calculated

3 (USP, 2000). All experiments were carried out in triplicate.

\section{$4 \quad 2.6$ In vitro protein release}

A Franz diffusion Cell fitted with a $0.45 \mu \mathrm{m}$ pore cellulose acetate membrane filter

6 was used to monitor in vitro protein release (Leitner et al., 2004). The receptor

7 compartment contained $\mathrm{pH} 7.4$ Phosphate buffer maintained at $37^{\circ} \mathrm{C} \pm 1^{\circ} \mathrm{C}$. Microparticles

8 ( 10mg) were deposited on the membrane at the air-liquid interface established by the

9 filter. At selected times, $250 \mu \mathrm{l}$ of the buffer was sampled from the receptor compartment

10 and the volume replaced. The quantity of BSA-FITC released was determined using UV

11 spectrophotometry as mentioned before. The in vitro drug release data were fitted in the

12 Korsmeyer-Peppas (KP) equation, $M_{t} / M_{\infty}=K t^{n}$, where $M_{t} \& M_{\infty}$ corresponds to the amount of

13 drug released at time $\mathrm{t}$ and $\infty$ respectively, $\mathrm{k}$ is the kinetic constant, $\mathrm{t}$ is the release time 14 and $\mathrm{n}$ is the diffusional component for drug release.

\section{$15 \quad 2.7$ Cell culture}

Calu-3 cells, an adenocarcinoma cell line derived from a 25 year old Caucasian male were purchased from the American Type Culture Collection (Rockville, Md., USA) at passage 14 and used between passages 20 and 50 (Grainger et al., 2006).

\subsection{Cell viability}

Calu- 3 cells were plated at a density of $3 \times 10^{4} /$ well in a 96 -well format at $37^{\circ} \mathrm{C}$ in $5 \%$

$21 \mathrm{CO}_{2}$. After 24 hours of culture, a suspension containing $2 \mathrm{mg}$ of empty (unloaded)

22 microparticles per $\mathrm{ml}$ of growth media was added to each well and incubated for either 4 or

236 hours at $37^{\circ} \mathrm{C}$ and $5 \% \mathrm{CO}_{2}$. Cellular viability was assessed using the MTT (3-(4,5- 
1 dimethylthiazol-2-yl)-2,5-diphenyltetrazolium bromide) colorimetric assay (Gupta et al., 2 2004).

\subsection{Microparticle application on calu-3 monolayers}

$6 \mathrm{CO}_{2}$. For cells cultured under LLI (liquid-liquid interphase) conditions, $500 \mu \mathrm{l}$ of media was

7 added to the apical chamber and $1500 \mu$ to the basolateral chamber. For cells cultured at an ALI (air-liquid interface) condition, the apical culture medium was removed 1 day after

9 seeding and the basolateral medium was reduced to $650 \mu$. For both culture conditions, the media was replaced once daily. Blank microparticles were impinged on the monolayers on

11 the $12^{\text {th }}$ day after seeding. In the case of LLI monolayers, the apical media was aspirated

12 and the basolateral volume was reduced to $650 \mu \mathrm{l}$ before impingement. ALI grown

13 monolayers were used as such. For the application of microparticles, the multi-well plate with the monolayers was placed in an airtight container as shown in Fig. $1.1 \mathrm{mg}$ of the microparticles was weighed into the DPI. The vacuum pump was adjusted to deliver a constant suction. Filter inserts containing the monolayers were each placed in the first well

17 under the tube. Microparticles were aerosolized onto the monolayers for 3 seconds. The 18 inserts were then returned to their respective wells.

19 To obtain data on the reproducibility of particle deposition, pre-weighed Transwell ${ }^{\circledR}$ inserts

20 containing no cells $(n=5)$ were slightly wetted with water and treated as described above for 21 each polymer. After impingement, the inserts were left to dry and reweighed to determine 22 the quantity deposited. 


\section{$1 \quad$ 2.9.1 Fluorescein-sodium transport across Monolayers}

After particles were aerosolized onto the cell monolayers, the filter inserts were placed into new wells containing $1500 \mu$ l of bicarbonated Krebs-Ringer (KRB) solution in the basolateral compartment. $500 \mu \mathrm{l}$ of a $50 \mu \mathrm{M}$ sodium fluorescein (flu-Na) solution in KRB was added to the apical compartment of each well. $100 \mu \mathrm{l}$ samples were taken at predetermined intervals up to 4hours from the basolateral compartment and replaced with an equal amount of fresh buffer. The fluorescence of flu-Na was measured in 96 well plates using a fluorescence plate reader (Wallac Victor, Perkin Elmer, Cambridge, United Kingdom) at excitation and emission wavelengths of 488 and 530nm respectively. The apparent permeability coefficient values were calculated using the following equation:

$$
P_{\text {app }}=\left(1 / A C_{0}\right) d Q / d t
$$

where Q, cumulative amount of $\mathrm{Na}$-flu permeated across the cell monolayers over time $\mathrm{t}$; $\mathrm{A}$, surface area of transwells $\left(1.12 \mathrm{~cm}^{2}\right)$; $\mathrm{C}_{0}$, initial Na-flu concentration in the apical chamber.

\subsubsection{Bioelectric measurements}

Trans-epithelial electrical resistance (TEER) was measured with an $\mathrm{EVOM}^{\circledR}$ Epithelial Voltohmmeter device equipped with "chopstick electrodes" (World Precision Instruments, Sarasota, FL. USA). Monolayers grown under LLI conditions were used directly. Monolayers grown under ALI conditions had $750 \mu \mathrm{l}$ and $1500 \mu \mathrm{l}$ of prewarmed media added to the apical and basolateral sides, respectively, and were allowed to equilibrate for $10 \mathrm{~min}$ in an incubator before the TEER was measured. TEER was expressed as $\Omega \mathrm{cm}^{2}$ after subtracting from the reading the resistance of the supporting filter and multiplying it by the surface area of the monolayer. 


\section{$1 \quad$ 2.9.3 Cytokine Release}

2 Basolateral media collected after 4 hours exposure to the microparticles were

3 analyzed for IL-8 levels using ELISA MAX ${ }^{\mathrm{TM}}$ Kit (Biolegend, Inc.,San Diego, CA, USA). The

4 assay detection limit was $30 \mathrm{pg} / \mathrm{ml}$. Collected media was diluted with the sample diluent and 5 analyzed following protocols mentioned in the kit.

\section{$6 \quad 2.10$ Statistical Analysis}

7 Results are expressed as mean \pm SD. One way ANOVA was used to test for

8 differences between treatments. In cases where the differences in the mean values were 9 significant, post hoc pair wise comparisons were done using Neumann-Keuls multiple 10 comparison tests. A p value $<0.05$ was taken as significant.

\section{$11 \quad 3.0$ Results}

\section{$12 \quad 3.1$ Size, density and water content}

The particle size of the microspheres obtained after spray drying was dependent on 14 the concentration (polymer and protein) of the spray solution and the spray flow rate 15 (amount of compressed air needed to spray the solution). These parameters were 16 optimised to obtain particles in the respirable size range. Table 1 gives the density and

17 geometric diameter in $\mu \mathrm{m}$ of the microparticles. The density was least in the case of HPC-L 18 microspheres $\left(0.09 \pm 0.02 \mathrm{~g} / \mathrm{cm}^{3}\right)$ and highest in the case of chitosan microspheres $19 \quad\left(0.28 \pm 0.02 \mathrm{~g} / \mathrm{cm}^{3}\right)$.

20 The theoretical aerodynamic diameter of individual particles, daer, is related to the 21 geometric diameter $\mathrm{d}$ (assuming particle sphericity) by the following expression:

$$
d_{\text {aer }}=d \times \sqrt{ }\left(\rho / \square \square \square \rho_{1}\right)
$$


1 where $\square \rho \square \square$ is the particle density and $\square \square \square \rho_{1}$ is $1 \mathrm{gm} / \mathrm{cm}^{3}$ (Hinds, 1999). The daer was

2 calculated for each (Table 1) and found to be in the range 1-3 $\mu \mathrm{m}$.

3 The Scanning Electron micrographs (Figure 2) show that the particles were smooth

4 and spherical in the case of PLGA and alginate. Chitosan and sodium hyaluronate particles

5 were spheroidal and corrugated. Ovalbumin and gelatin particles were toroidal and smooth.

6 Particles made of HPC were crumpled. The water content (WC) from TGA analysis was

7 least in the case of PLGA particles $(0.49 \pm 0.01 \% \mathrm{w} / \mathrm{w})$ and highest in the case of ovalbumin 8 particles $(10.47 \pm 0.76 \% w / w)($ Table 1$)$.

\section{$9 \quad 3.2$ Protein loading, stability and distribution}

10 The protein loading was determined as outlined in section 2.4 and compared with 11 the theoretical loading to calculate protein encapsulation efficiency (\%EE). \%EE was

12 highest in the case of Alginate microspheres $(96.9 \pm 0.55 \%)$ and least in the case of microspheres manufactured from Chitosan $(59.2 \pm 0.78 \%) . \% E E$ for the other polymers was $62.6 \pm 1.2 \%$ (PLGA), $95.8 \pm 1.2 \%$ (gelatin), $88.9 \pm 1.3 \%$ (HPC), $96.7 \pm 1.4 \%$ (ovalbumin), and $89.2 \pm 1.2 \%$ (sodium hyaluronate). The effect of spray drying on the structural integrity of BSA was investigated using SDS-PAGE. No degraded protein fragments or covalent aggregates could be detected in all the formulations tested (data not shown).

CLSM can be used as a non-destructive visualization technique for microparticles containing a fluorescently labeled protein (Lamprecht et al., 2000). A homogeneous distribution of BSA-FITC can be seen within the loaded polymeric particles except in the

21 case of gelatin and PLGA (Fig. 3). In the batches of PLGA and chitosan, empty 22 microspheres were seen which may explain their relatively low \%EE compared to the other 23 polymers. 


\section{$1 \quad 3.3$ Aerosolization efficiency}

Microparticles blended with mannitol were aerosolised at $60 \mathrm{l} / \mathrm{min}$ through a DPI using an Andersen cascade impactor. The deposition data (Table 2) was calculated taking into account the assay values of the microparticles. The recovered dose (RD) ranged between $83-95 \%$ of the loaded dose. The Fine particle fraction (FPF) was highest in the case of HPC-L particles (26.1\%) and lowest with Ovalbumin particles (11.9\%). The other polymers produced FPF values between $14-21 \%$. The MMAD values were larger than the theoretical $d_{a e r}$ (calculated in section 3.1) and ranged between $2.9-4.7 \mu \mathrm{m}$ possibly due to particle aggregation. Emitted dose uniformity for all formulations as tested using DUSA were in the acceptable range (80.9-91\%). The values were $82.4 \pm 7.5 \%$ (chitosan), $84.4 \pm 6.1 \% \quad$ (alginate), $85.5 \pm 8.7 \% \quad$ (PLGA), $80.9 \pm 2.3 \% \quad$ (gelatin), $91.1 \pm 4.5 \% \quad$ (HPC), $81.3 \pm 3.2 \%$ (ovalbumin), and $80.2 \pm 2.6 \%$ (sodium hyaluronate).

\subsection{In-vitro protein release}

To determine the effect of polymers on protein release rates, studies were carried out as described in section 2.6. Figure 4 shows the cumulative BSA-FITC release profiles from the microparticles. At the end of 3 hours, near complete release was seen with particles made of HPC and gelatin. Release from PLGA particles was negligible $(\sim 0.2 \%)$. For all other polymers, the release ranged between $17-43 \%$ after 3 hours. Application of the Peppas model to determine release kinetics resulted in coefficient of determination $\left(R^{2}\right)$ values between 0.93-0.99 for all polymers except PLGA. The diffusion component (n) ranged between $0.39-0.43$ for alginate, chitosan, gelatin, ovalbumin and sodium hyaluronate. The value of $n$ was 0.65 for HPC. 


\section{$1 \quad 3.4$ Polymer toxicity}

\section{$2 \quad 3.4 .1$ MTT assay}

For the MTT assay, a particle dose of $2 \mathrm{mg} / \mathrm{ml}$ was used based on the theoretical

4 concentration of dry powder that would deposit in the central and intermediate lung after

5 inhalation of a standard 40mg dose (Newman et al., 2002; Widdicombe, 2002; Newhouse

6 et al., 2003). Table 3 shows that after 4 or 6 hours exposure to the microparticles, no

7 significant difference $(p>0.05)$ in viability was observed between the cells treated with

8 microparticles and the untreated control cells.

\section{$9 \quad$ 3.4.2 Bioelectric measurements}

TEER measurements were used in order to assess the effect of the polymers on the

11 tight junctional integrity of Calu-3 cell monolayers. From deposition reproducibility studies

12 with blank filters, it was found that $576 \pm 128 \mu \mathrm{g}$ of microparticles was delivered on each

13 insert (area of insert: $1.1 \mathrm{~cm}^{2}$ ) using the apparatus shown in Figure 1. The exposure dose

14 used is approximately 250 times greater than what would be expected based on the

15 ICRP66 model (ICRP, 1994). Prior to particle impingement, cells grown under LLI

16 conditions exhibited a mean TEER value of $1870 \pm 48 \Omega \mathrm{cm}^{2}$ and those grown under ALI

17 conditions exhibited a mean value of $774 \pm 16 \Omega \mathrm{cm}^{2}$. On removal of apical media from the

18 LLI monolayers for particle impingement, a sharp drop in electrical resistance was

19 observed which did not recover during the course of the study. Four hours post treatment, a

20 further drop in TEER was observed for monolayers treated with chitosan, gelatin, sodium

21 hyaluronate and ovalbumin. Three days later, the TEER values for the treated cells had

22 recovered to values between $450-650 \Omega \mathrm{cm}^{2}$ for all polymers except PLGA and ovalbumin. A

23 TEER value $\geq 450 \Omega \mathrm{cm}^{2}$ is indicative of a tight calu-3 monolayer (Sanjar et al., 2001). In 
1 contrast, monolayers grown under ALI conditions showed no significant drop in TEER value

2 after treatment except in the case of PLGA and ovalbumin microparticles (Figure 5). After 3

3 days however, TEER values returned to initial levels for all treated cells except those 4 impinged with PLGA.

\subsubsection{Transport study with Sodium Fluorescein}

The transport of a paracellular marker, sodium fluorescein across Calu-3 cell

7 monolayers, cultured under ALI and LLI conditions, was studied in the presence of

8 impinged microparticles. Flux and $\mathrm{P}_{\text {app }}$ were calculated from a plot of the cumulative

9 amount of $\mathrm{Na}$-Flu transported as a function of time. Only PLGA and ovalbumin caused a

10 significant increase in Na-Flu transport $(p<0.05)$ (Table 3). An increase in Na-Flu transport

11 was also seen with chitosan for cells cultured under ALI conditions, although this was not 12 significant.

\section{$13 \quad 3.4 .4$ Cytokine production}

14 Upon stimulation by immunogenic airborne particulates, airway epithelial cells release cytokines such as Interleukin-8 (IL-8) which attracts and activates inflammatory 16 cells in the airways and contributes to the pathogenesis of airway disorders. After 4 hours 17 of apical exposure to the polymeric microparticles, polarized calu-3 cells secreted IL-8 at 18 levels from 240-2100pg/ml consistent with previous studies (Witschi et al., 1999). As shown 19 in Table 3, IL-8 production was significantly increased $(p<0.05)$ from the control (air 20 impinged) monolayers in the case of gelatin and PLGA.

\section{4. Discussion}

Spray drying produced microspheres with a protein encapsulation efficiency 23 between $59-97 \%$. The microspheres had a calculated aerodynamic diameter ( $d_{a e r}$ ) in the 
1 range $1-3 \mu \mathrm{m}$ and particles with a daer between $0.02-0.05 \mu \mathrm{m}$ and $2-5 \mu \mathrm{m}$ are capable of

2 alveolar deposition (Hanes et al., 2003).

A homogenous protein distribution within all the polymeric particles except gelatin and PLGA (as seen by CLSM) is expected since the feed to the spray dryer is a neat solution of the protein and polymer dissolved in purified water. The punctate and nonuniform distribution of BSA within the gelatin microspheres produced from a neat solution could indicate a protein-protein interaction. In the case of PLGA particles where a w/o emulsion was used, BSA could be expected to accumulate at the water-solvent interface because of its surfactant properties. The fluorescent corona seen in this case is similar to 10 those previously reported (Lamprecht et al., 2000).

When aerosolized alone, the forces generated within the DPI were insufficient to entrain the microparticles as a result of poor flow and particle aggregation. Entrainment was aided by the addition of a coarse carrier, mannitol (Chan et al., 1997). In addition to powder entrainment, one of the key factors that determines FPF is the ability of the inhaler

15 to generate forces sufficient to deagglomerate the microparticles from the carrier. The FPF values for the polymeric microparticles in the present study were $12-26 \%$. The degree to 17 which the microparticles are released from mannitol during aerosolisation is influenced by 18 factors such as the size of the microparticles, their shape, surface roughness and moisture content. In the case of irregularly shaped particles or those with a rough surface, the area of contact is reduced. These particles are thought to experience reduced adhesive forces 21 (Maugis, 1996). The SEMs indicated a polymer dependent difference in the shape and 22 surface properties of the microparticles manufactured in this study. The collapsed, raisin23 like shape of HPC particles coupled with a low residual moisture content could have 
1 facilitated deagglomeration resulting in a relatively high FPF (Table 2). The low FPF seen

2 with ovalbumin particles could be due to particle aggregation as a result of high residual

3 moisture. Incomplete powder deaggregation in the DPI could have also resulted in the

4 experimental MMADs of the microparticles being 2-3 times larger than the theoretical

5 aerodynamic diameter, daer (Bosquillon et al., 2001) as calculated in Table 1.

The amount of liquid available for the dissolution of a therapeutic aerosol in the

7 lungs is very small (Patton, 1996). For protein release studies, open membrane systems

8 have been employed previously as a representative technique (Witschi et al., 1999). A

9 novel approach using Franz diffusion cells was used in this study (Franz, 1975). These

10 cells are not suited for prolonged drug release studies because of evaporation of release

11 media from the lower compartment. This is a limitation of the device. No pharmacopoieal

12 methods are presently available to understand drug release from a formulation following its

13 deposition in the lungs. The diffusion coefficient $(n)$ values with the KP equation were less

14 than $\leq 0.43$ for alginate, chitosan, gelatin, ovalbumin and sodium hyaluronate particles

15 indicating protein release by Fickian diffusion through water-filled pores in the polymer

16 network (Peppas, 1985). Matrix swelling/erosion effects were not evident possibly due to

17 the small volume of release media that seeps into the upper chamber. Polymer relaxation

18 effects were seen however with HPC particles. The $\mathrm{n}$ value in this case was 0.65 indicating

19 anomalous (non-Fickian) release kinetics. Drug release rates in the case of Fickian

20 diffusion is governed by factors such as polymer hydrophilicity, pore size of the polymer

21 network and overall net charge carried by the protein/polymer. One or more of the above

22 factors could have contributed to the differences in protein release rate observed between

23 the polymers. The rapid release observed with gelatin could be due to the uncoiling of its 
1 triple helical structure when exposed to body temperatures. In the case of HPC, both

2 diffusion and polymer erosion combined to give a high release rate. Sodium Hyaluronate

3 displayed the lowest release rate (excluding PLGA). This could indicate that it underwent

4 hydration more rapidly than the other polymers. Hydration produces a gelatinous mass, the

5 thickness of which then determines the diffusional path length for the protein. The longer

6 the path length, the slower would be the rate of release (Sujja-areevath et al., 1998;

7 Surendrakumar et al., 2003). Negligible protein release from PLGA particles could be

8 attributed to its strongly hydrophobic nature resulting in poor wetting. Indeed the $t_{1 / 2}$ for

9 hydrolysis of PLGA in the lungs is expected to be in the order of several months (Dunne et

10 al., 2000). Chitosan and sodium hyaluronate appear best suited for sustained release of

11 proteins/peptides in the lungs. Their mucoadhesive properties could also be exploited to

12 reduce particle clearance by ciliary movement. Another important factor in sustained

13 release to the lungs using microparticles is alveolar macrophage avoidance. Some

14 strategies to reduce particle phagocytosis include coating with phospholipids, precoating

15 with BSA and nonproteinaceous macromolecules (Cryan, 2005), and control of the particle

16 size and density (Edwards et al., 1997).

17 The polymers considered in the present study have all received the G.R.A.S

18 (Generally Regarded As Safe) status from the US FDA. However the toxicity of a

19 substance varies greatly with the route of administration and excipients considered safe for

20 ingestion may not be safe for inhalation. Upon inhalation and release of the drug payload,

21 the polymers and their degradation products must be non-toxic and non-immunogenic. It is

22 believed that exposure of lung epithelial cells to foreign particulate matter can cause

23 disruption of the epithelial tight junctions and formation of intercellular channels for the 
1 passage of molecules from airway lumen to blood. The MTT assay indicated no major

2 cytotoxicity up to 6 hours after exposure of the cells with the polymeric microparticles.

3 Exposure of submerged cell monolayers to suspended particles is a traditional approach to 4 study particle-cell interactions and their effect on monolayer integrity. To better mimic the in 5 vivo situation of an air-liquid interface, a novel method was devised in this study to impinge 6 dry microparticles directly on to calu-3 cells grown on porous supports. Inspite of the extremely high particle exposure dose, after 72 hours cytotoxicity was

8 observed only with ovalbumin and PLGA (under LCC conditions) and only with PLGA 9 (under ALI conditions). Consistent with the TEER observations, Papp values for sodium 10 fluorescein were highest in the case of PLGA and ovalbumin (Table 3). Alteration of the 11 barrier function could occur by a number of mechanisms including tyrosine phosphorylation 12 or dislocation of junctional proteins (Atkinson et al., 2001) or interaction of cationic species 13 with the negatively charged glycocalyx of cell membranes (Yu et al., 1994).

14 A decrease in epithelial integrity on treatment with ovalbumin has previously been 15 reported (Evans et al., 2002). In this study, treatment of ALI cultured Calu-3 cells caused 16 only a transient disruption of the barrier properties and TEER recovered to pre17 impingement values after 24 hours. The increase in $\mathrm{P}_{\text {app }}$ for sodium fluorescein in the 18 presence of chitosan (though not significant) for cells under ALI culture is consistent with 19 previous studies showing the epithelial permeability enhancing effects of chitosan (Smith et 20 al., 2004). The transient opening of epithelial tight junctions in the case of ovalbumin and 21 chitosan could be exploited for absorption enhancement in systemic protein delivery via the 22 lungs. 
Production of the inflammatory cytokine, IL-8 was significantly increased $(p<0.05)$ in

2 the case of PLGA and gelatin microparticles which is indicative of their immunogenicity.

3 The highest secretion $(1964 \pm 219 \mathrm{pg} / \mathrm{ml})$ was observed in the case of gelatin. This could be

4 due to endotoxin contamination in the raw material used (Witschi et al., 1999).

\section{5. Conclusion}

While the concept of controlled and targeted delivery is well established for oral and

7 parenteral use, its application for pulmonary drug delivery is a new area lacking

8 fundamental data. Commercial formulations based on these technologies have yet to make

9 it to market and this can be attributed in some part to the lack of comparable data of

10 potential excipients, concerns regarding the safety and clearance of these polymeric

11 carriers from the lungs and the dearth of standardised biopharmaceutical testing methods

12 for the pulmonary route. In this paper, a comprehensive comparison of a range of protein-

13 loaded polymeric particles for inhalation was conducted. The effects of the polymers on the

14 delivery and release of proteins in the lungs and their biocompatibility was modelled using

15 innovative methods. From our studies certain polymers would appear suited to meet

16 different respiratory delivery needs eg. high delivery efficiency (HPC), low toxicity and

17 controlled release (sodium hyaluronate and chitosan), and improved systemic delivery

18 (ovalbumin and chitosan). Interestingly, one of the most commonly studied excipients for

19 controlled release in the lungs, PLGA, had the greatest toxicity of the polymers studied.

\section{Acknowledgements}

21 The authors acknowledge Mr. Neal Leddy for assistance with the SEM and Dr. Nadia Ben

22 Larbi for help with the CLSM. This research was supported by the Science Foundation

23 Ireland (Grant 05/RFP/ENG0020). 


\section{References:}

Abe, S., Takizawa, H., Sugawara, I., Kudoh, S., 2000. Diesel exhaust (DE)-induced cytokine expression in human bronchial epithelial cells: a study with a new cell exposure system to freshly generated DE in vitro. Am J Respir Cell Mol Biol, 22, 296-303.

Atkinson, K. J., Rao, R. K., 2001. Role of protein tyrosine phosphorylation in acetaldehyde-induced disruption of epithelial tight junctions. Am J Physiol Gastrointest Liver Physiol, 280, G1280-1288.

Bivas-Benita, M., van Meijgaarden, K. E., Franken, K. L., Junginger, H. E., Borchard, G., Ottenhoff, T. H., Geluk, A., 2004. Pulmonary delivery of chitosan-DNA nanoparticles enhances the immunogenicity of a DNA vaccine encoding HLA$A^{*} 0201$-restricted T-cell epitopes of Mycobacterium tuberculosis. Vaccine, 22, 16091615.

Blank, F., Rothen-Rutishauser, B. M., Schurch, S., Gehr, P., 2006. An optimized in vitro model of the respiratory tract wall to study particle cell interactions. J Aerosol Med, 19, 392-405.

Boer, A. H. d., Grietje, M., Henderik, W. F., 2001. Pulmonary Drug Delivery: Delivery To and Through the Lung. In: Molema, G.,Meijer, D. K. F. (Ed.), Drug Targeting Organ-Specific Strategies, Wiley-VCH Verlag GmbH, pp. 53-88.

Bosquillon, C., Lombry, C., Preat, V., Vanbever, R., 2001. Influence of formulation excipients and physical characteristics of inhalation dry powders on their aerosolization performance. J Control Release, 70, 329-339.

Chan, H. K., Clark, A., Gonda, I., Mumenthaler, M., Hsu, C., 1997. Spray dried powders and powder blends of recombinant human deoxyribonuclease (rhDNase) for aerosol delivery. Pharm Res, 14, 431-437.

Cryan, S. A., 2005. Carrier-based strategies for targeting protein and peptide drugs to the lungs. Aaps J, 7, E20-41.

Dunne, M., Corrigan, I., Ramtoola, Z., 2000. Influence of particle size and dissolution conditions on the degradation properties of polylactide-co-glycolide particles. Biomaterials, 21, 1659-1668.

Edwards, D. A., Hanes, J., Caponetti, G., Hrkach, J., Ben-Jebria, A., Eskew, M. L., Mintzes, J., Deaver, D., Lotan, N., Langer, R., 1997. Large porous particles for pulmonary drug delivery. Science, 276, 1868-1871.

Evans, S. M., Blyth, D. I., Wong, T., Sanjar, S., West, M. R., 2002. Decreased distribution of lung epithelial junction proteins after intratracheal antigen or lipopolysaccharide challenge: correlation with neutrophil influx and levels of BALF sE-cadherin. Am J Respir Cell Mol Biol, 27, 446-454. 
Fiegel, J., Fu, J., Hanes, J., 2004. Poly(ether-anhydride) dry powder aerosols for sustained drug delivery in the lungs. J Control Release, 96, 411-423.

Foster, K. A., Avery, M. L., Yazdanian, M., Audus, K. L., 2000. Characterization of the Calu-3 cell line as a tool to screen pulmonary drug delivery. Int J Pharm, 208, 111.

Franz, T. J., 1975. Percutaneous absorption on the relevance of in vitro data. J Invest Dermatol, 64, 190-195.

Grainger, C. I., Greenwell, L. L., Lockley, D. J., Martin, G. P., Forbes, B., 2006. Culture of Calu-3 cells at the air interface provides a representative model of the airway epithelial barrier. Pharm Res, 23, 1482-1490.

Gupta, M., Gupta, A. K., 2004. In vitro cytotoxicity studies of hydrogel pullulan nanoparticles prepared by AOT/N-hexane micellar system. J Pharm Pharm Sci, 7, 38-46.

Gupta, R. K., Chang, A. C., Griffin, P., Rivera, R., Guo, Y. Y., Siber, G. R., 1997. Determination of protein loading in biodegradable polymer microspheres containing tetanus toxoid. Vaccine, 15, 672-678.

Hanes, J., Dawson, M., Har-el, Y., Suh, J., Fiegel, J., 2003. Gene Delivery to the Lung. In: Hickey, A. J. (Ed.), Pharmaceutical Inhalation Aerosol Technology, Marcel Dekker, Inc., New York, pp. 489-539.

Hinds, W. C., 1999. Aerosol Technology: Properties, Behavior, and Measurement of Airborne Particles. In: (Ed.), John Wiley \& Sons, New York, pp.

Huang, Y., Yeh, M., Chiang, C., 2002. Formulation factors in preparing BTMchitosan microspheres by spray drying method. Int J Pharm, 242, 239-242.

ICRP, 1994. International Commission on Radiological Protection (ICRP), Human respiratory tract model for radiological protection: A report of a Task Group of the International Commission on Radiological Protection, ICRP Publication 66, Pergamon Press, Oxford.

Igartua, M., Hernandez, R. M., Esquisabel, A., Gascon, A. R., Calvo, M. B., Pedraz, J. L., 1998. Stability of BSA encapsulated into PLGA microspheres using PAGE and capillary electrophoresis. International Journal of Pharmaceutics, 169, 45.

Knebel, J. W., Ritter, D., Aufderheide, M., 2002. Exposure of human lung cells to native diesel motor exhaust--development of an optimized in vitro test strategy. Toxicol In Vitro, 16, 185-192.

Kohn, J. B., Pulapura, S., Schwartz, A., Bahulekar, R., 2007.Polyarylates for drug delivery and tissue engineering, US Patent 7271234, 18 Sep. 
Lamprecht, A., Schafer, U., Lehr, C. M., 2000. Structural analysis of microparticles by confocal laser scanning microscopy. AAPS PharmSciTech, 1, E17.

Leitner, V. M., Guggi, D., Krauland, A. H., Bernkop-Schnurch, A., 2004. Nasal delivery of human growth hormone: in vitro and in vivo evaluation of a thiomer/glutathione microparticulate delivery system. J Control Release, 100, 87-95.

Mack, G. S., 2007. Pfizer dumps Exubera. Nat Biotechnol, 25, 1331-1332.

Maugis, D., 1996. On the contact and adhesion of rough surfaces. Journal of adhesion science and technology, 10, 161-175.

Morimoto, K., Katsumata, H., Yabuta, T., Iwanaga, K., Kakemi, M., Tabata, Y., Ikada, Y., 2000. Gelatin microspheres as a pulmonary delivery system: evaluation of salmon calcitonin absorption. J Pharm Pharmacol, 52, 611-617.

Newhouse, M. T., Hirst, P. H., Duddu, S. P., Walter, Y. H., Tarara, T. E., Clark, A. R., Weers, J. G., 2003. Inhalation of a dry powder tobramycin PulmoSphere formulation in healthy volunteers. Chest, 124, 360-366.

Newman, S. P., Busse, W. W., 2002. Evolution of dry powder inhaler design, formulation, and performance. Respir Med, 96, 293-304.

Okamoto, H., Todo, H., Lida, K., Danjo, K., 2002. Dry Powders for Pulmonary Delivery of Peptides and Proteins. KONA, 20, 71-83.

Patton, J. S., 1996. Mechanisms of macromolecule absorption by the lungs. Adv Drug Deliv Rev, 19, 3-36.

Patton, J. S., Platz, R. M., 1992. (D) Routes of delivery: Case studies: (2) Pulmonary delivery of peptides and proteins for systemic action. Advanced Drug Delivery Reviews, 8, 179.

Peppas, N. A., 1985. Analysis of Fickian and non-Fickian drug release from polymers. Pharm Acta Helv, 60, 110-111.

Robledo, R. F., Barber, D. S., Witten, M. L., 1999. Modulation of bronchial epithelial cell barrier function by in vitro jet propulsion fuel 8 exposure. Toxicol Sci, 51, 119125.

Sakagami, M., Kinoshita, W., Sakon, K., Sato, J., Makino, Y., 2002. Mucoadhesive beclomethasone microspheres for powder inhalation: their pharmacokinetics and pharmacodynamics evaluation. J Control Release, 80, 207-218.

Sakagami, M., Sakon, K., Kinoshita, W., Makino, Y., 2001. Enhanced pulmonary absorption following aerosol administration of mucoadhesive powder microspheres. J Control Release, 77, 117-129. 
Sanjar, S., Matthews, J., 2001. Treating systemic diseases via the lung. J Aerosol Med, 14 Suppl 1, S51-58.

Scheuch, G., Kohlhaeufl, M. J., Brand, P., Siekmeier, R., 2006. Clinical perspectives on pulmonary systemic and macromolecular delivery. Adv Drug Deliv Rev, 58, 9961008.

Sethuraman, V. V., Hickey, A. J., 2002. Powder properties and their influence on dry powder inhaler delivery of an antitubercular drug. AAPS PharmSciTech, 3, E28.

Sham, J. O., Zhang, Y., Finlay, W. H., Roa, W. H., Lobenberg, R., 2004. Formulation and characterization of spray-dried powders containing nanoparticles for aerosol delivery to the lung. Int J Pharm, 269, 457-467.

Smith, J., Wood, E., Dornish, M., 2004. Effect of chitosan on epithelial cell tight junctions. Pharm Res, 21, 43-49.

Suarez, S., O'Hara, P., Kazantseva, M., Newcomer, C. E., Hopfer, R., McMurray, D. N., Hickey, A. J., 2001. Respirable PLGA microspheres containing rifampicin for the treatment of tuberculosis: screening in an infectious disease model. Pharm Res, 18, 1315-1319.

Sujja-areevath, J., Munday, D. L., Cox, P. J., Khan, K. A., 1998. Relationship between swelling, erosion and drug release in hydrophillic natural gum mini-matrix formulations. European Journal of Pharmaceutical Sciences, 6, 207.

Surendrakumar, K., Martyn, G. P., Hodgers, E. C., Jansen, M., Blair, J. A., 2003. Sustained release of insulin from sodium hyaluronate based dry powder formulations after pulmonary delivery to beagle dogs. J Control Release, 91, 385-394.

USP, 2000. Aerosols, Metered Dose Inhalers, and Dry Powder Inhalers. United States Pharmacopoiea, USP 24, NF 19, 1895-1912.

Widdicombe, J. H., 2002. Volume of airway surface liquid in health and disease. Am J Respir Crit Care Med, 165, 1566.

Witschi, C., Mrsny, R. J., 1999. In vitro evaluation of microparticles and polymer gels for use as nasal platforms for protein delivery. Pharm Res, 16, 382-390.

Yu, X. Y., Schofield, B. H., Croxton, T., Takahashi, N., Gabrielson, E. W., Spannhake, E. W., 1994. Physiologic modulation of bronchial epithelial cell barrier function by polycationic exposure. Am. J. Respir. Cell Mol. Biol., 11, 188-198.

Zahoor, A., Sharma, S., Khuller, G. K., 2005. Inhalable alginate nanoparticles as antitubercular drug carriers against experimental tuberculosis. International Journal of Antimicrobial Agents, 26, 298. 
Zeng, X. M., Martin, G. P., Marriott, C., 1995. Preparation and in vitro evaluation of tetrandrine-entrapped albumin microspheres as an inhaled drug delivery system.

European Journal of Pharmaceutical Sciences, 3, 87.

\section{Tables:}

Table 1: Size, density and water content of polymeric microparticles (mean $\pm S D, n=3$ )

\begin{tabular}{|c|c|c|c|c|}
\hline Polymer & $\begin{array}{c}\text { Geometric } \\
\text { diameter } \\
(\mathbf{d})(\mu \mathrm{m})\end{array}$ & $\begin{array}{c}\text { density }(\rho) \\
\left(\mathbf{g} / \mathbf{c m}^{3}\right)\end{array}$ & $\begin{array}{c}\mathbf{d}_{\mathrm{ae}}(\mu \mathrm{m}) \\
\square \square \square \square\end{array}$ & $\begin{array}{c}\text { Water } \\
\text { content } \\
(\%)\end{array}$ \\
\hline Chitosan & $5.49 \pm 0.32$ & $0.28 \pm 0.02$ & 2.91 & $5.03 \pm 0.17$ \\
\hline
\end{tabular}




\begin{tabular}{|c|c|c|c|c|}
\hline Alginate & $3.23 \pm 0.25$ & $0.22 \pm 0.02$ & 1.52 & $6.73 \pm 0.09$ \\
\hline PLGA & $5.5 \pm 0.41$ & $0.11 \pm 0.02$ & 1.82 & $0.49 \pm 0.01$ \\
\hline Gelatin & $2.88 \pm 0.2$ & $0.18 \pm 0.02$ & 1.22 & $4.84 \pm 0.07$ \\
\hline HPC-L & $4.61 \pm 0.16$ & $0.09 \pm 0.04$ & 1.38 & $1.8 \pm 0.08$ \\
\hline Ovalbumin & $4.29 \pm 0.38$ & $0.11 \pm 0.05$ & 1.42 & $10.47 \pm 0.76$ \\
\hline $\begin{array}{c}\text { Sodium } \\
\text { Hyaluronate }\end{array}$ & $3.61 \pm 0.35$ & $0.12 \pm 0.02$ & 1.25 & $3.22 \pm 0.05$ \\
\hline
\end{tabular}

Table 2: Deposition in an anderson cascade impactor after aerosolisation of mannitol blended microparticles from a DPI at $60 \mathrm{l} / \mathrm{min}$ (mean $\pm S D, n=3$ )

\begin{tabular}{|l|c|c|c|}
\hline Polymer & FPF $(\%)^{\mathbf{a}}$ & MMAD $^{\mathbf{b}}$ & GSD $^{\mathbf{c}}$ \\
\hline Chitosan & $15.4 \pm 5.1$ & $3.9 \pm 0.2$ & $2.06 \pm 0.1$ \\
\hline Alginate & $20.7 \pm 6.1$ & $4.1 \pm 0.3$ & $1.88 \pm 0.07$ \\
\hline PLGA & $13.9 \pm 4.3$ & $2.9 \pm 0.2$ & $2.05 \pm 0.1$ \\
\hline Gelatin & $18.9 \pm 4.8$ & $4.7 \pm 0.4$ & $1.92 \pm 0.12$ \\
\hline HPC-L & $26.1 \pm 3.9$ & $3.3 \pm 0.6$ & $1.91 \pm 0.05$ \\
\hline Ovalbumin & $11.9 \pm 4.3$ & $4.2 \pm 0.3$ & $1.85 \pm 0.1$ \\
\hline Sodium Hyaluronate & $19.9 \pm 7.2$ & $4.6 \pm 0.2$ & $1.89 \pm 0.2$ \\
\hline
\end{tabular}

aFPF is the Fine Particle Fraction

bMMAD is the Mass Median Aerodynamic Diameter

'GSD is the Geometric Standard Deviation

Table 3: Toxicity and immunogenicity of microparticles in Calu-3 cells: Papp of Fluorescein Sodium, cell viability and cytokine release

\begin{tabular}{|c|c|c|c|c|c|}
\hline \multirow[t]{3}{*}{ Treatment } & \multicolumn{2}{|c|}{$\begin{array}{l}\text { Papp }\left(\times 10^{-7} \mathrm{~cm} / \mathrm{sec}\right) \\
\text { of Fluorescein Sodium }\end{array}$} & \multirow{2}{*}{\multicolumn{2}{|c|}{$\begin{array}{c}\% \text { cell viability }{ }^{*} \\
\text { Exposure }\end{array}$}} & \multirow[t]{3}{*}{$\begin{array}{c}\mathrm{IL}-8 \\
(\mathrm{pg} / \mathrm{ml})^{*}\end{array}$} \\
\hline & \multirow{2}{*}{ ALI } & \multirow{2}{*}{ LLI } & & & \\
\hline & & & 4 hours & 6hours & \\
\hline Air ims & 1.19 & $0.85 \pm 0.02$ & NA & NA & $274 \pm 33$ \\
\hline HPC-L & $1.38 \pm 0.22$ & $1.28 \pm 0.27$ & $101 \pm 3$ & $89 \pm 5$ & $382 \pm 64$ \\
\hline Alginate & $1.61 \pm 0.23$ & $1.71 \pm 0.28$ & $91 \pm 18$ & $82 \pm 12$ & $352 \pm 87$ \\
\hline Chitosan & $2.29 \pm$ & $1.28 \pm 0.17$ & $97 \pm 2$ & $95 \pm 2$ & $467 \pm 108$ \\
\hline Gela & & & $83 \pm$ & & $1964 \pm 219^{\ddagger}$ \\
\hline Sodium & 1.66 & & 85 & $78+7$ & $417 \pm 83$ \\
\hline Ovalbu & 11.9 & $20.72 \pm 1.88^{\ddagger}$ & $129 \pm 23$ & $113 \pm 2$ & $468 \pm 51$ \\
\hline PLGA & $9.52 \pm 3.29$ & $6.91 \pm 1.15^{\ddagger}$ & $98 \pm 2$ & $97 \pm 1$ & $538 \pm 108^{\ddagger}$ \\
\hline
\end{tabular}

* Mean $\pm S D(n=4),{ }^{\ddagger}$ Significantly different compared to control $(\mathrm{p}<0.05)$ 


\section{Figure Legends:}

Figure 1: Apparatus used for particle impingement on cell monolayers.

Figure 2: Scanning electron micrographs of BSA loaded microparticles: Alginate (A); Chitosan (B); PLGA (C); Gelatin (D); Sodium Hyaluronate (E); Ovalbumin $(\mathrm{F})$; $\mathrm{HPC}(\mathrm{G})$

Figure 3: Confocal Laser Scanning Microscopy images of microparticles containing BSA-FITC (green), Differential Interference contrast image(grey); A,B: Alginate; C,D: Chitosan; E,F: PLGA; G,H: Gelatin

Figure 4: Protein release profiles from spray-dried microparticles carried out using Franz diffusion cell (Mean $\pm S D, n=3$ )

Figure 5: Time course of change in TEER values in calu-3 cell monolayers after exposure to polymeric microparticles under ALI conditions (Mean $\pm S D, n=4$ ) 
Figure 1:

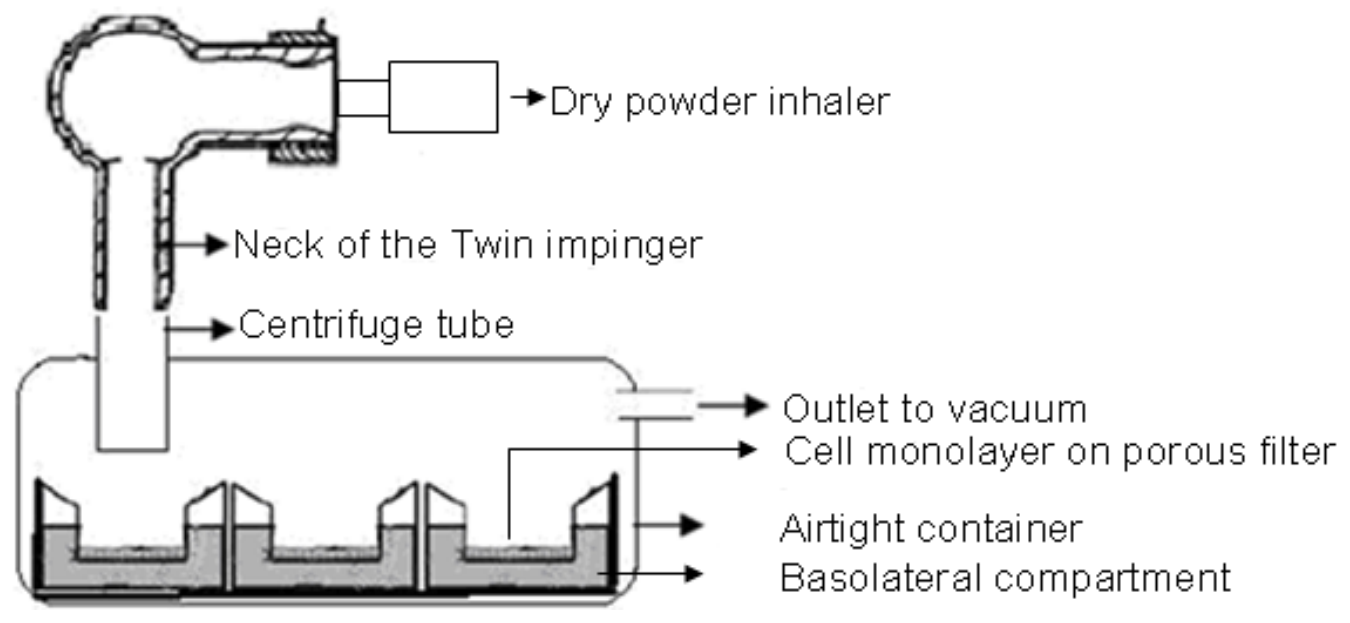


Figure 2:

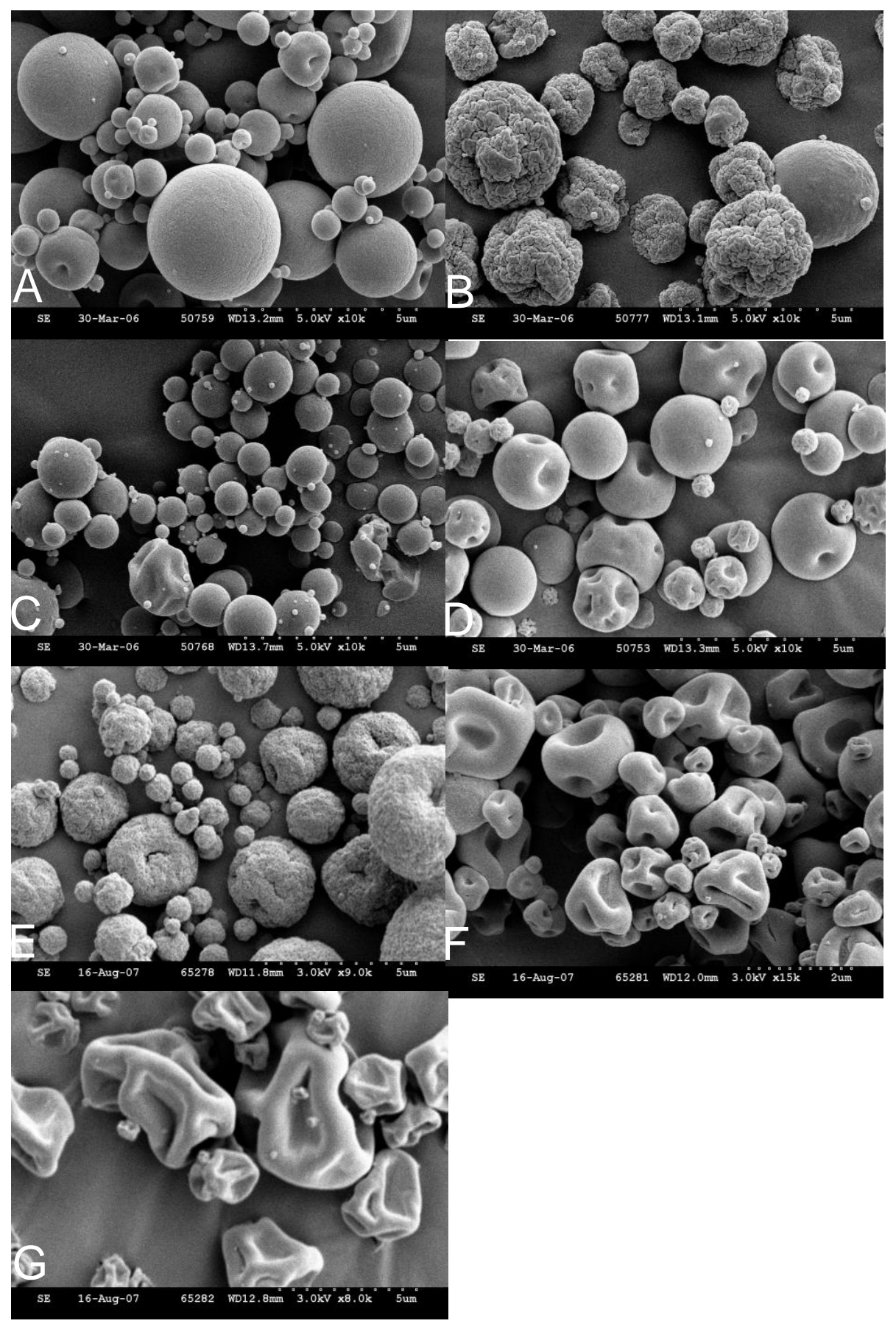


Figure 3:

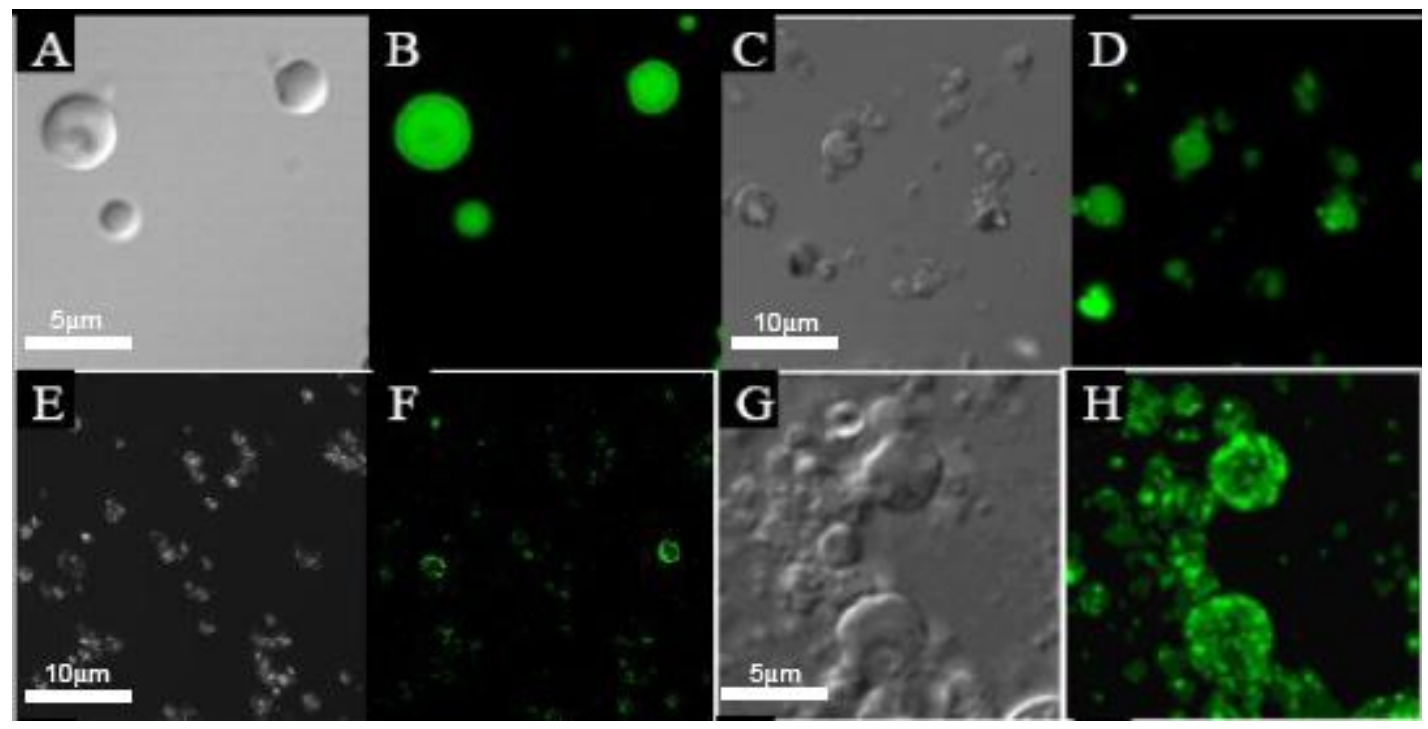


Figure 4:

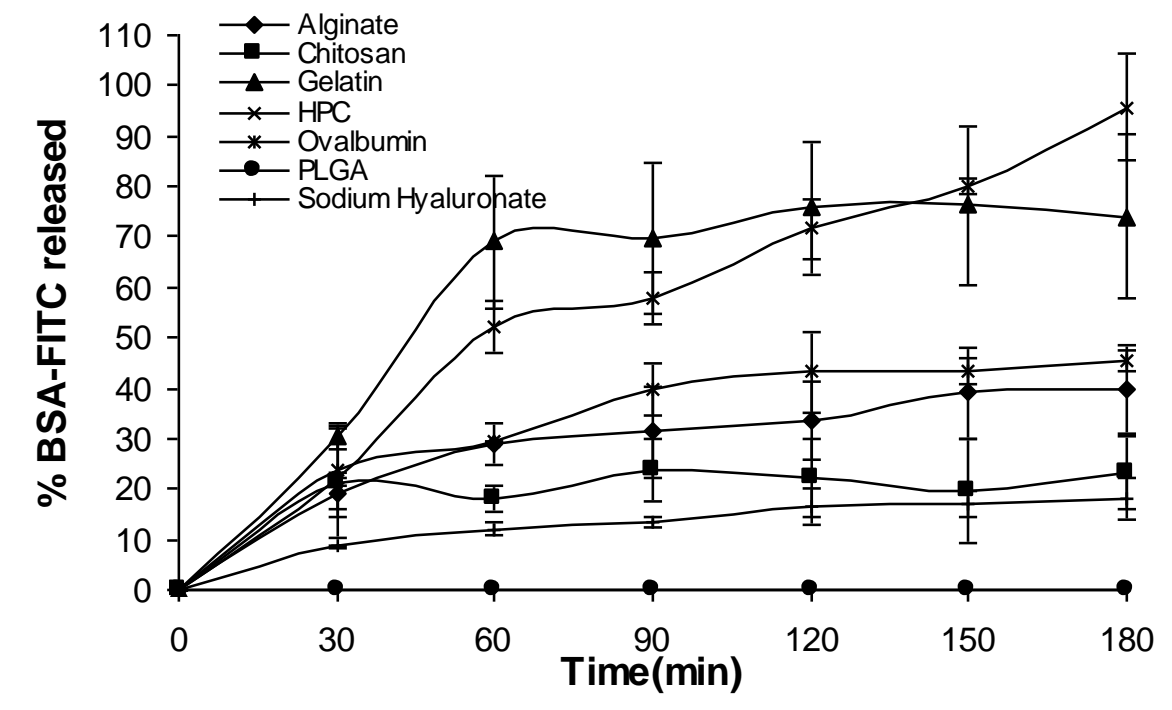


Figure 5:
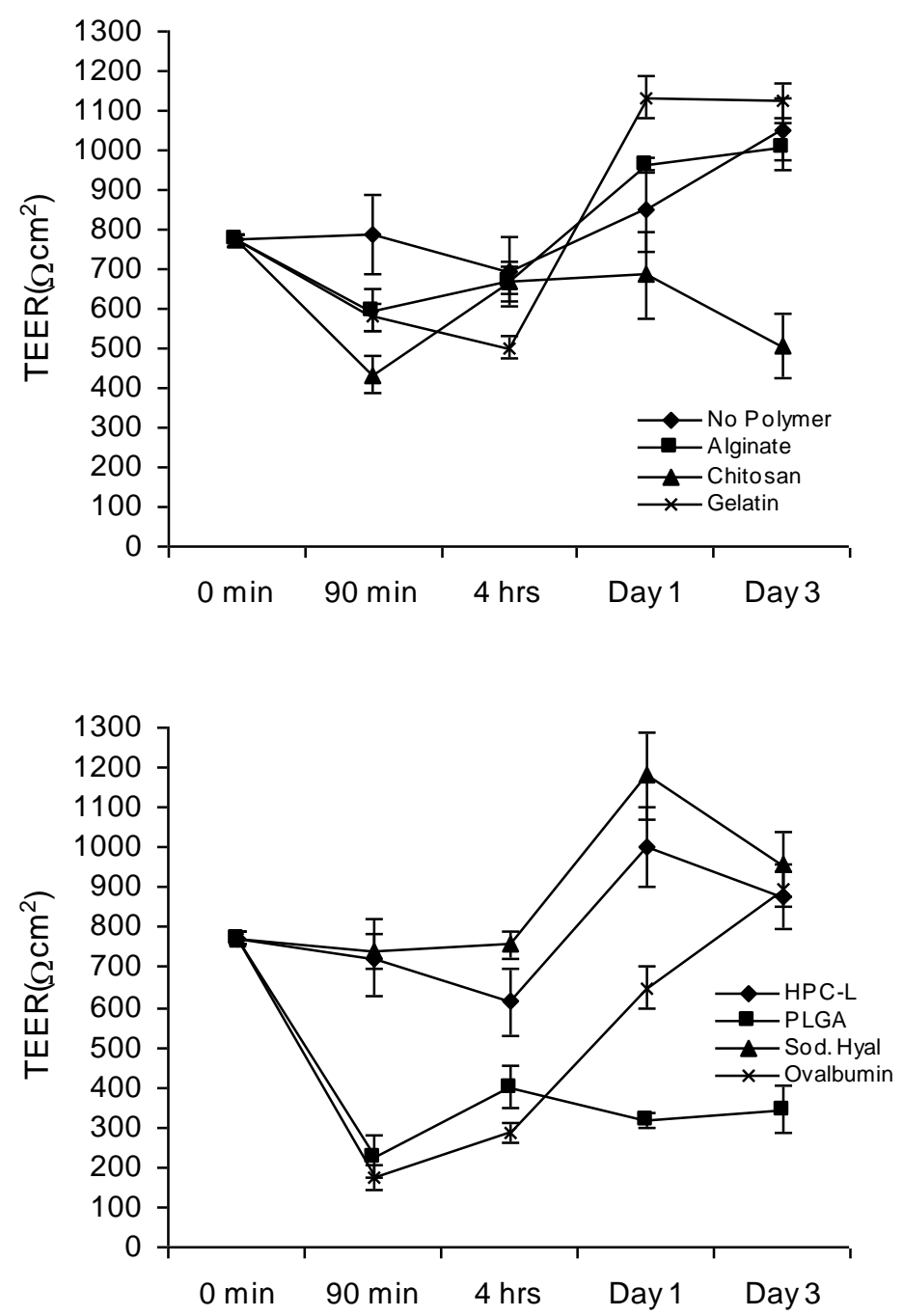